\title{
Review of Gas Turbine Combustion Chamber Designs to Reduce Emissions
}

\section{Fawzi Shnain Alnasur ${ }^{1}$, Raheem Dohan Owayez ${ }^{2}$, Khaldoon Hussein Hamzah ${ }^{3}$}

\author{
${ }^{1}$ Assistant Lecturer, College of Science, Al-Qadisiyah University, Al-Qadisiyah, Iraq \\ ${ }^{2,3}$ Assistant Lecturer, Department of Materials Engineering, University of Al-Qadisiyah /College of Engineering, Al-Qadisiyah-Iraq
}

\begin{abstract}
Ensuring the environmental safety of aircraft engines is an important task for developers. This problem is becoming more urgent due to an increase in engine power, since an increase in power is achieved primarily by increasing the temperature in the combustion chamber, leading to an increase in $\mathrm{NO}_{x}$ emissions. In this study, the problem of emission in the aviation industry and ways to solve it were considered. Separately, the method of reducing emissions by changing the design of combustion chambers was considered in more detail.
\end{abstract}

Keywords-emission, combustion chamber, swirler, atomizer, vortex, stabilizing.

\section{INTRODUCTION}

One of the main global problems of mankind is the restoration and improvement of its habitat. One of the main sources of environmental pollution are transport systems, in particular, aircraft gas turbine engines, so reducing emissions of harmful substances in exhaust gases is one of the main tasks at the stage of creation and environmental modernization of the gas turbine power plant combustion chambers. Pollutant emissions (nitrogen oxides $\left(\mathrm{NO}_{\mathrm{x}}\right)$, carbon monoxide (CO), unburned hydrocarbons (UHC) and smoke) are normalized by the International Civil Aviation Organization (ICAO) requirements for the environmental performance of aircraft engines increase every year $[1,2]$

Combustion chamber is the main component of the gas turbine engine, which determines its environmental characteristics. An important role in the combustion chamber is played by the combustion zone, which determines the burning rate of the fuel-air mixture, the range of stable operation, the thermal state of the flame tube elements, the emission and launchers characteristics of the chamber. The processes in this part of the combustion chamber largely depend on the design and operation mode of the base element of the frontal area - a vortex gas burner.

The main difficulties in creating a combustion chamber with low emissions of harmful substances are due to the fact that in order to reduce the output of $\mathrm{CO}$ and $\mathrm{NO}_{\mathrm{x}}$, it is necessary to carry out mutually opposite measures. The rational design of the combustion chamber should constitute a compromise between the requirements arising from the task of reducing the emissions of these two groups of pollutants $\left(\mathrm{CO}\right.$ and $\mathrm{NO}_{\mathrm{x}}$ ). This can be achieved by improving the workflow of the primary zone [3], the intermediate and delution zones [4], the rational choice of the volume of the flame tube and the residence time in the combustion chamber [5]. The principle of operation of all low-emission combustion chambers is based on maintaining the temperature in the combustion zone(s) in a fairly narrow range in all engine operating conditions (Fig. 1). 


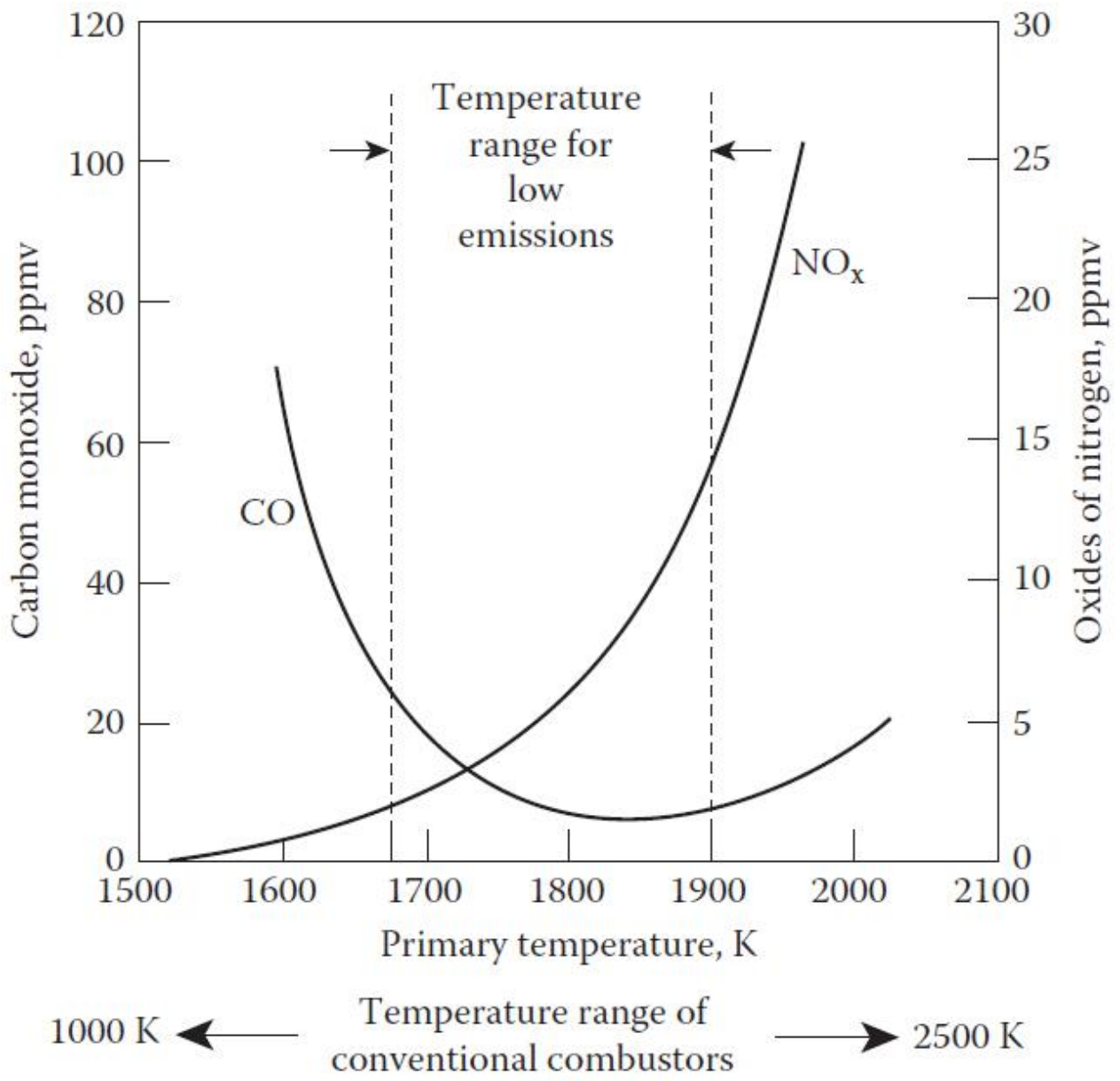

Fig. 1. Temperature range with low emissions of CO (p.p.m) and NOx (p.p.m), (p.p.m is a unit of concentration in parts per million) [4]

To reduce the emission of harmful substances by other methods, it is necessary to develop combustion chambers of complex construction with an increase in the combustion zones number, each of which is optimized for a particular mode of operation. At the same time, to ensure promising standards for the emission of harmful substances, it is necessary to create combustion chambers that would allow at the same time to reduce all types of harmful components.

\section{THE MAIN CHARACTERISTICS OF THE DESIGN OF THE COMBUSTION CHAMBER}

The development stages of the traditional combustion chamber scheme of the gas turbine engines can be represented from the diagrams presented in Fig. 2, illustrate the logical development of the principle of workflow organization in the combustion chamber of the most common scheme. There are respectively a large variants number of the basic scheme shown in Fig. 2, d. However, in the general case, the design of any gas turbine engine combustion chamber always has the following main elements: a housing, a diffuser, a flame tube and an atomizer. 
(a)

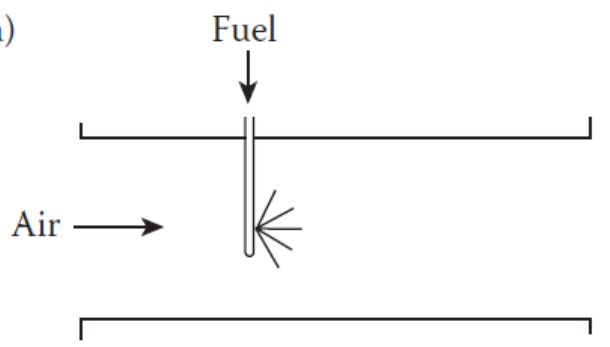

(c)

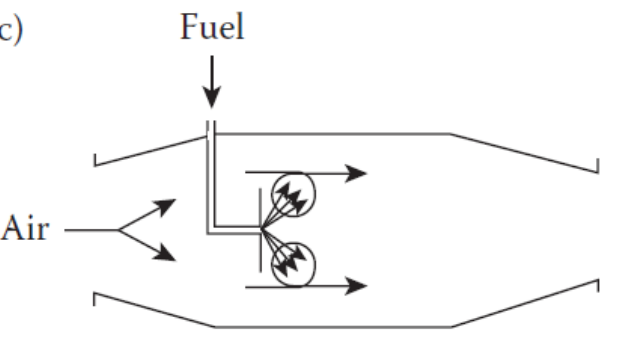

(b)

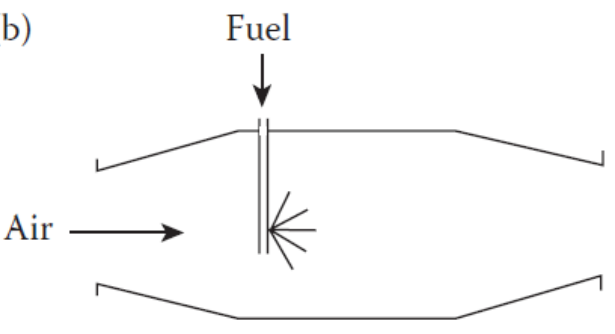

(d)

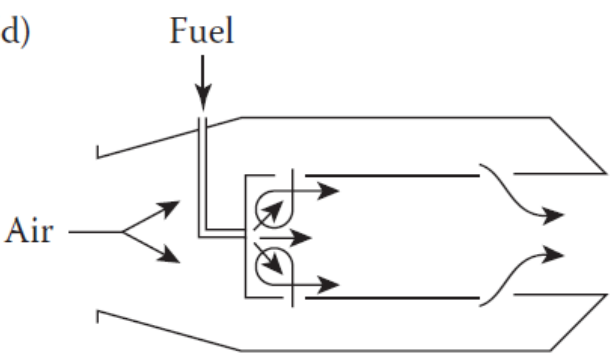

Fig.2: Stages of the development Schematic of the traditional combustion chamber of a gas turbine engine [3]

Further development and improvement of gas turbine engines required a significant change in the combustion chamber design. These changes affect the combustion chambers of engines used in aviation, in which high values of pressure and temperature are realized, with a longer resource, high reliability of work and minimum concentration of toxicity and smoke of exhaust products.

In fig. 2. a. there is no constant pressure in the combustion zone, part of the compression energy generated by the compressor is wasted, no complete combustion of the fuel, the pressure loss is proportional to the square of the speed of the air flow. In fig.2.b. braking zones have been created (air velocity is reduced along the inner surface of the combustion chamber), it is impossible to fully control the air velocity and prevent processes such as flame separation, which is necessary to maintain a steady burning process. In fig. 2. to achieve the required temperature, a ratio is required that its concentration may exceed the upper flammability limit (re-enriched fuel).

\section{LOW EMISSION COMBUSTION CHAMBERS}

The combustion chamber shown in fig. 3 is an example of an unusual and ingenious design. Even more significant design changes may be required in order to satisfy the very stringent restrictions now imposed on emissions of harmful substances. The main problem with the development of combustion chambers has been and remains to obtain good starting characteristics, a wide range of stable combustion, high combustion efficiency, minimum soot formation, which must be ensured by a volume-limited combustion zone, in one of which fuel is injected. Since some of the listed requirements are contradictory, the resulting characteristics are inevitably the result of a compromise. Recently, this situation has been complicated by the requirements to reduce emissions of harmful substances; However, reducing emissions of carbon monoxide and unburned hydrocarbons is achieved at the cost of increasing the opacity and the content of nitrogen oxides in exhaust gases. With this in mind, the urgent need for radical changes in the design of the combustion chamber becomes obvious. 


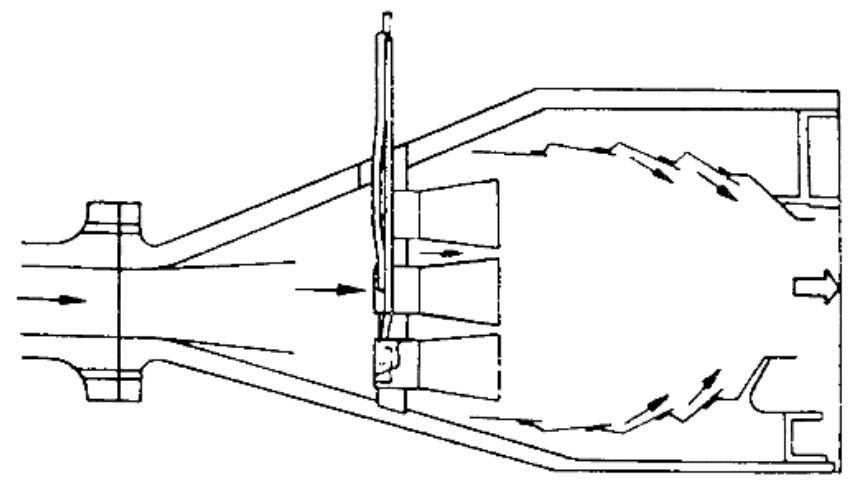

Fig.3: The design of the combustion chamber with a system of vortex burners of modules [6]

One of the possible approaches is to use in one form or another "variable geometry", i.e., to regulate the flow areas and, therefore, the amount of air entering the primary combustion zone. At high pressures to reduce to a minimum the formation of smoke and nitrogen oxides air is supplied in large quantities. At low pressures, the primary air is throttled, as a result of which the fuel/air ratio increases and the velocity of the air flow in the primary zone decreases. This increases the completeness of combustion of fuel (as well as reduces emissions of carbon monoxide and unburned hydrocarbons) in the idle mode and improves start-up characteristics [7].

Another approach involves the use of two separate combustion zones, each of which is optimized for operation, respectively, on low and high power modes. A typical dualzone combustion chamber should have a weakly forced primary combustion zone, which, with an excess fuel ratio of $\varphi \approx 0.8$, would ensure high combustion efficiency and low emissions of carbon monoxide and unburned hydrocarbons. Such a primary zone should provide an increase in the gas temperature sufficient for low power regimes and serve as a source of hot gas for a downstream main combustion zone into which a fully mixed mixture of fuel and air could be fed. When operating at full power, the fuel should be supplied to both zones, and the value of $\varphi$ in them should be maintained at a sufficiently low level, close to 0.6 , which minimizes the emission of nitrogen oxides and smoke. [8]

By using twelve flameholder designs the emissions of NOx, CO and unburned hydrocarbons (UHC) are reported for a lean premixed propane-air system at $800 \mathrm{~K}$ and $1 \mathrm{MPa}$ inlet conditions. The flameholders approved six design concepts with two values of blockage for each concept. The principal determinant of emissions performance is pressure drop of the flameholder. Designs producing larger pressure drops and less $\mathrm{NO}_{\mathrm{x}}, \mathrm{CO}$ and UHC emissions. For all designs, the lean stability limit equivalence ratio is approximately 0.35 . Flashback velocities is ranged from $30 \mathrm{mls}$ to $40 \mathrm{mls}$. The flameholder with a perforated plate was operated with a velocity of $23 \mathrm{mls}$ through perforations at equivalence ratio 0.7 without producing flashback. [9]

In fig. 4. A schematic view shows of the vorbix represents a new approach to a gas turbine combustor design. To increase the mixing and combustion rates, the Rayleigh instability of swirling flows was exploited. Two-stage fuel system combination with a piloted combustor leads to high rate technique for fuel preuaporization within the combustor proper. The results show that this combustor has uncommon performance characteristics that include perfect stability and high combustion efficiency over wide excursions in operating fuel air ratios in addition to substantially reduced emission levels during high power operation. [10] 


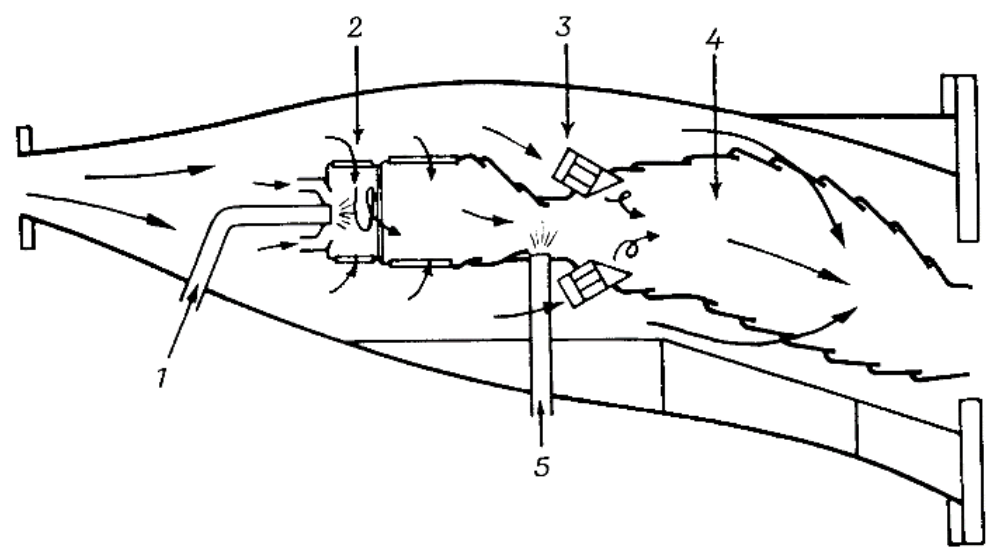

Fig. 4: The vorbix burner (acronym for Vortex Burning and Mixing) [10]

1 - pilot gas injection; 2 - pilot tubular zone of combustion; 3 - swirlers: 4 - main annular zone of combustion; 5 main gas injection.

Vorbix, designed by Pratt-Whitney under a contract with NASA. The first stage is a traditional design of an annular combustion chamber with 30 swirlers and centrifugal atomizer that feed fuel to the combustion zone. Air, necessary for complete combustion with a small value of $\varphi$, is supplied to the main combustion zone of the chamber through 60 vortex burners located on both sides of the flame tube. The high level of turbulence generated by these vortex burners provides intensive mixing of the fuel with hot combustion products coming from the primary zone and the rapid completion of the combustion process. [11]
To determine how equivalence ratio and residence time effect on exhaust emissions with premixed, prevaporized propane fuel, a flame-tube study was performed. Nitrogen oxides emissions of $0.3 \mathrm{~g} \mathrm{NO} 2 / \mathrm{kg}$ fuel were measured with more than 99 percent combustion efficiency at inlet temperature of $800 \mathrm{~K}$ and an equivalence ratio of 0.4. By burning very lean with relatively long residence times it was obtained constant combustion efficiency, lower nitrogen oxides emissions. [12]

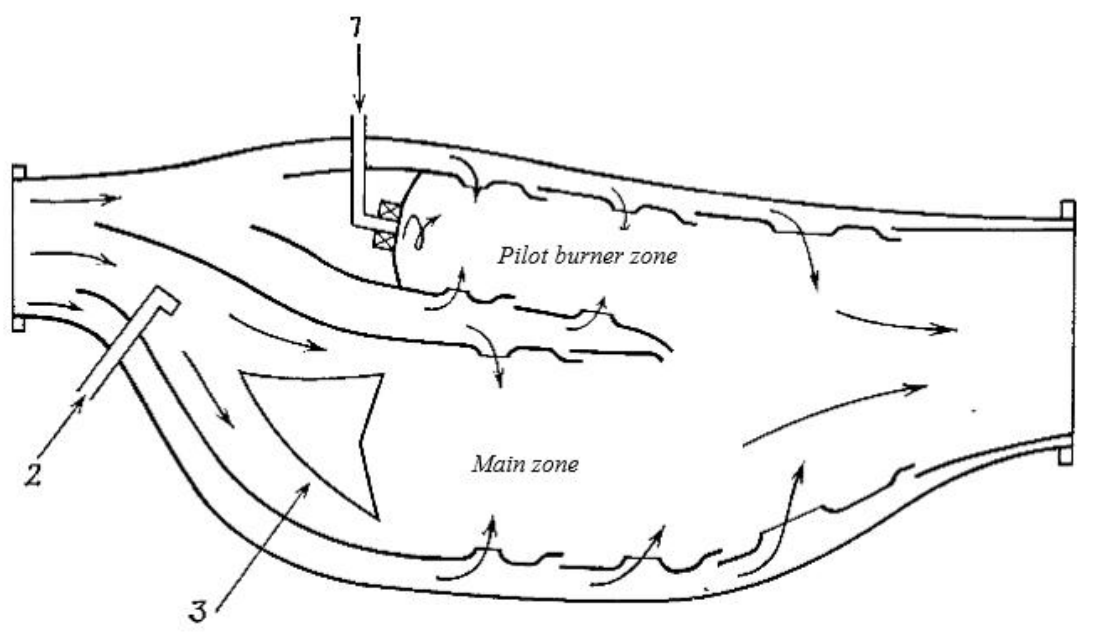

Fig. 5: Two-stage annular combustion chamber [12]

1 -pilot gas injection; 2 - main gas injection; 3 - pre-mixing channel. 
In Fig.5. a schematic of a two-zone, two-tier annular combustion chamber developed by General Electric, also for NASA. This combustion chamber has two annular combustion zones. The outer zone - the stage of low gas - is designed to operate under conditions typical of the low gas mode. This stage serves simultaneously as a pilot zone of combustion for the inner main zone, which is used in all other engine operating modes [13].

Also led the developers to the technology of the organization of the combustion process of the air-fuel mixture using a large number of atomizers to solve the environmental safety of the combustion chamber. There are publications that present the results of the development and research of the combustion chamber operation with the number of atomizers from 100 to $600[14,15,16]$. The main advantage of this technology is high controllability of the combustion process.

The multi-discharge low-emission combustion chamber of the engines of OAO Kuznetsov (Samara, Russian Federation) [17]. It was shown that the proposed layout of the multi-burner combustion chamber allows to ensure environmental safety and high reliability of the engine operation in various operating modes.

Currently, studies are underway to reduce emissions of nitrogen oxides in such combustion chambers. These studies have shown that the use of multifocal burning in the combustion chamber of a traditional scheme makes it possible to reduce the level of $\mathrm{NO}_{\mathrm{x}}$ emission by $10 \ldots 15 \%$. In this regard, it was proposed to divide the combustion zone into 2 areas - a pilot one and a main one. To implement such a scheme, a complex and expensive automatic fuel control system was introduced. This ensured the reduction of nitrogen oxide emissions by $30 \ldots 35 \%$. However, as can be seen, this is not enough to achieve the promising regulatory requirements described above. Therefore, research and development in this direction continues. These developments use an integrated approach that includes the following areas:

- improvement of the working process in the combustion chamber;

- determination of the optimal parameters of the thermodynamic cycle of the gas turbine engine as a whole;

- increase the efficiency of individual engine components;

- Determination of the optimal degree of bypass gas turbine engine;

- improvement and cheapening of the fuel supply system;

- transition to alternative types of fuel: liquefied natural gas, hydrogen $[18,19]$.

In the design of the frontal area of the serial annular combustion chamber, vortex gas burners (Fig. 6) are installed evenly around the circumference between the inner and outer walls of the flame tube [20].

The fuel supplied by the gas atomizers 1 along the axis of each burners is mixed in the mixing chamber 3 with the air flow swirling in the swirler 2.

As a result, in the primary zone of the combustion chamber behind the nozzle extension 4 of each vortex burners, flows of the fuel-air mixture are formed, which have axial circulation areas. The presence of such areas ensures the circulation of hot combustion products and active centers from the combustion zone to the torch root of the fresh mixture, which creates conditions for stable ignition and flame stabilization. 


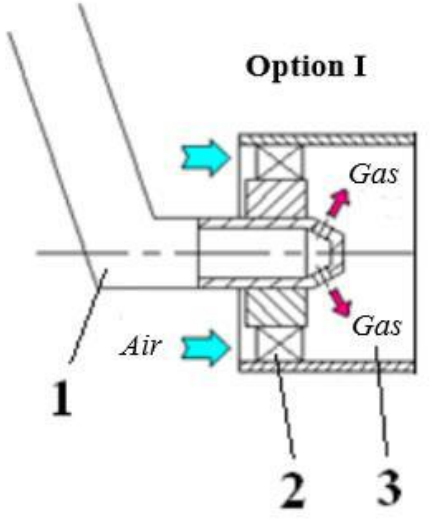

Option II

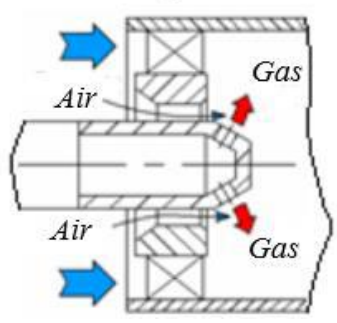

Fig.6: Schematic of burner circuit: [20]

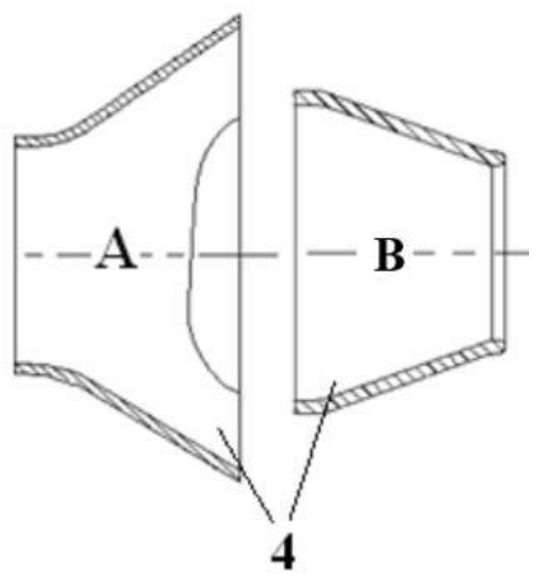

1-simplex atomizer, 2-swirler, 3-mixing chamber, 4-nozzle extension

In fig. 7. A low-emission gas turbine combustion chamber operating predominantly on compressed gas with low emissions of nitrogen oxides and carbon oxides is presented. It contains frontal area and a cylindrical flame tube with air holes located around the circumference of the flame tube. The frontal area consists of at least two modules with cavities pre-mixing the fuel with air. The ratio of the distance between the axes of adjacent modules to the internal diameter of the flame tube is $0.4-0.5$. The ratio of the length of the pre-mixing cavity of each module to the diameter of its output nozzle is $0-6-0.8$. The flame tube includes the combustion cavity of the air-fuel mixture and the mixing cavity of hot gases with air. The flame tube contains a continuous inner wall and an outer perforated shell, an annular channel between which is made with the possibility of supplying cooling air into the mixing cavity. The ratio of the combustion cavity length to the internal diameter of the flame tube is $09-11$. Holes for air supply are made in the mixing cavity. The invention reduces the emission of harmful substances due to the organization of "rich and poor" combustion of fuel through the implementation of premixing of fuel with air in the frontal area and eliminating the supply of cooling air into the combustion zone [21]. 


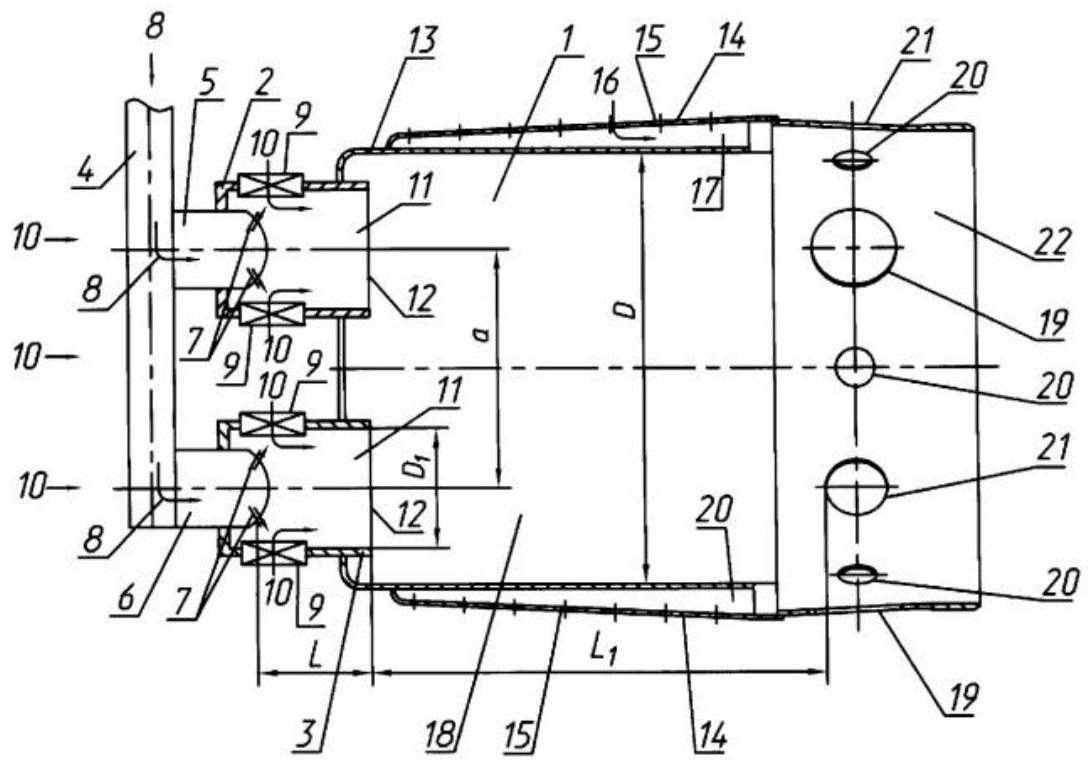

Fig.7: Low-emission combustion chamber of a gas turbine [22]

The gas turbine combustion system includes a combustion chamber having an end section and a precombustion section extending from the end section, a swirler, an optional pilot burner device, and a light-emitting device. Primary fuel is injected by the swirler into an inner volume of the pre-combustion section. The main flame is formed in the inner volume. The pilot burner device is installed in the end section of the combustion chamber and an pilot flame using the pilot fuel can be obtained inside the inner volume to stabilize the main flame. The light-emitting device emits electromagnetic radiation into the inner volume to stabilize the pilot and / or main flame. [23].



Fig.8: Schematic of Supplementary laser firing for combustion stability [24].

The fuel is introduced into the combustion system and its subsequent mixing with air by a critical aspect of the gas turbine engine performance. [25]. Premixing of fuel - air before burning in a DLE system can format "hot-spot" regions in the main combustion zone and increase the formation of thermal oxides of nitrogen $\left(\mathrm{NO}_{\mathrm{x}}\right)$ [25]. 
A multipoint ignition technique with a single-shot laser is proposed and its feasibility has been experimentally tested with the mixture of hydrogen and air. On the walls of the combustion chamber there are two conical cavities combined with a laser. The first cavity has a hole near the apex. Part of the incident laser energy was passed through the opening and irradiates into the second resonator by

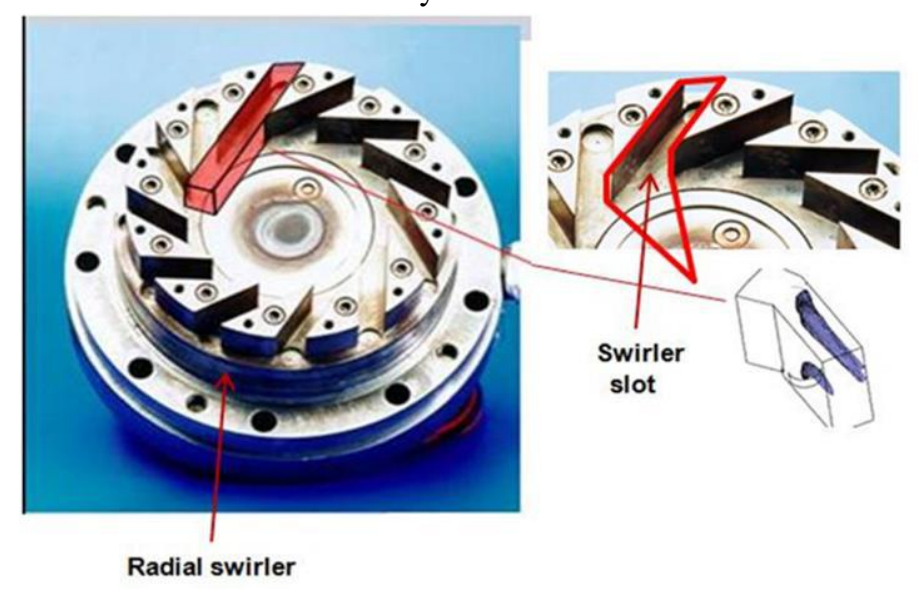

Radial swirler

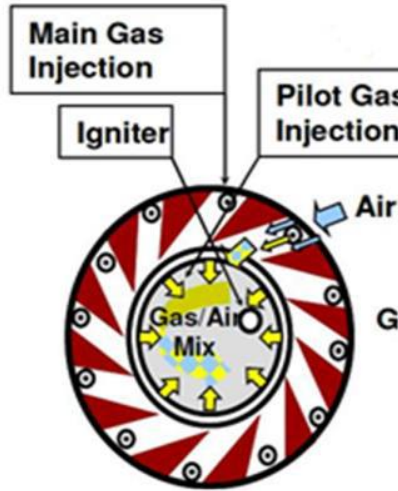

Plan view of the radial swirler directing unfocused laser beam into the first resonator. At the same time two-point ignition is achieved at each cavity. The method of simultaneous three-point ignition is based on the direction of a focused laser beam into a two-resonator device, which produces additional ignition in the center of the chamber by means of a laser-induced spark ignition. [26]

Fig.9: The radial swirler showing a rectangular slot.

Recently, a study was published in which the process of mixing fuel / air in a single slot in a radial swirler of a low-emission combustion system (DLE). fig. 9. [28]. It was shown that mixing in a swirler can be significantly improved by using the aerodynamic characteristics of the flow inside the slot.. [27, 40].

\section{CONCLUSIONS}

Reducing the emission of harmful substances in the combustion chamber is a very difficult task, as mentioned above there are different ways to solve this problem, while changing the design is an effective solution. The most optimal design showed the lowest emission concentrations of a modular low-emission combustion chamber where good fuel-air mixing takes place and forming a more uniform mixture (fuel and air), provides high-combustion efficiency which forms low emissions of smoke and gaseous pollutant species.

\section{REFERENCES}

[1] Annex 16 to the Convention on International Civil Aviation Organization. Environmental protection [Electronic resource]. In 2t. T.II. The emission of aircraft engines. (1.45 MB). ICAO, 2008. 
[2] Guidance material on aviation emissions charges related to local air quality, ICAO Journal First Edition - 2007.

[3] Lefebvre A. Gas turbine combustion. Wash.: Hemisphere Publ. Co., 1983. 531 p. (Russ. ed.: Lefebvre A. Protsessy v kamerakh sgoraniia GTD. Moscow: Mir Publ., 1986. 566 p.).

[4] Inozemtsev A.A., Sandratskij V.L. Gazoturbinnye dvigateli [Turbine engines]. Perm', 2006. 1204 p. (in Russian).

[5] Pchelkin Yu.M. Kamery sgoraniia gazoturbinnykh dvigatelej [Combustion chambers of gas turbine engines]: a textbook. 3rd ed. Moscow: Mashinostroenie Publ., 1984. 280 p. (in Russian).

[6] Roffe, G., \& Venkataramani, K. S. (1978). Emission measurements for a lean premixed propane/air system at pressures up to 30 atmospheres.

[7] Roffe, G., Venkataramani, K., \& DUERR, R. (1978, April). Experimental study of the effects of flameholder geometry on emissions and performance of lean premixed combustors. In 17th Aerospace Sciences Meeting (p. 187).

[8] Schadow, K. C., \& Gutmark, E. (1992). Combustion instability related to vortex shedding in dump combustors and their passive control. Progress in Energy and Combustion Science, 18(2), 117-132.

[9] Roffe, G., Venkataramani, K., \& DUERR, R. (1978, April). Experimental study of the effects of flameholder geometry on emissions and performance of lean premixed combustors. In 17th Aerospace Sciences Meeting (p. 187).

[10] Markowski S. J., Lohmann R. P., Reilly R. S. The VORBIX Burner-A New Approach to Gas Turbine Combustors //Journal of Engineering for Power. - 1976. - T. 98. - №. 1. C. $123-129$.

[11] Markowski, S. J., Johnson, B. V., \& Marshall, R. L. (1983, March). Combustion Experiments with a New Burner Air Distribution Concept. In ASME 1983 International Gas Turbine Conference and Exhibit (pp. V003T06A006V003T06A006). American Society of Mechanical Engineers.

[12] D.N. Anderson, Effects of Equivalence Ratio and Dwell Time on Exhaust Emissions from an Experimental Premixing Prevaporizing Burner, ASME Peper 75-GT-69, 1975.

[13] Marek, C. J., \& Papathakos, L. C. (1976). Exhaust emissions from a premixing, prevaporizing flame tube using liquid jet $\mathrm{A}$ fuel.

[14] Kuznetsov ND, Tokarev VV, Ivanov Yu.A. Multi-burner combustion chamber of "NK" engines, as a prototype of combustion chambers of promising gas turbine engines // Proceedings of CIAM No. 1229, 1987.

[15] Kuznetsov ND, Tokarev VV, Multi-burner combustion chambers are one of the promising directions for the development of engines // Problems of mechanical engineering and machine reliability. 1995. №2, S.

[16] Biryuk V., Kayukov, S., Zvyagintsev, V., Lysenko, U. Ways of speed increase for internal combustion engine fuel injectors // Research Journal of Applied Sciences. 2014. Volume 9, Issue 11, P. 721 .
[17] Biryuk, V.V., Gorshkalev, A.A., Lukachev, S.V., Tsybizov, Yu.I., Multi-burner combustion chamber - the basis of the technology for ensuring the environmental safety of aviation gas turbine engines, 2016 - №1 (17).

[18] Aviation and alternative aviation fuels. Working Paper A37WP / 23. Montreal: ICAO, 2010, 5 p.

[19] Epeikin L.F., Kryzhanovsky A.I., Lavrov V.N., Spivak Yu.V., Tsybizov Yu.I. Results of testing multi-burner combustion chambers of aviation gas turbine engines on alternative types of fuel. Vestnik SGAU. Series: Combustion, heat transfer and ecology of heat engines. 1998. Issue 1. Samara 1998. p. 141.

[20] A.N. Markushin, A.V. Baklanov, N.Ye. Tsyganov, Influence of the design of the burner device on the characteristics of the combustion chamber of a gas turbine engine operating on gaseous fuel, Vestnik Samara State Aerospace University, №3 (27), 2011

[21] Tashkinov V.A., Maksin V.I., Medvedev A.V., Baranov V.A. RU Patent No. 2,315,913 C2 "Low Emission Combustion Chamber of a Gas Turbine" IPC F23R 3/20. Published in 01/27/2008 (in Russian).

[22] A.V. Bubentsov, D. K. Vasilyuk, P. A. Golubev, R. E. Kirichenko, V. A. Tashkinov, B.V.Shoshin. (2014). Development of low-emission double-heat combustion chamber. Bulletin of the Samara State Aerospace University, No 3 (45), p. 25

[23] Cheng, R. K., Yegian, D. T., Miyasato, M. M., Samuelsen, G. S., Benson, C. E., Pellizzari, R., \& Loftus, P. (2000). Scaling and development of low-swirl burners for low-emission furnaces and boilers. Proceedings of the Combustion Institute, 28(1), 1305-1313.

[24] Dolmansley, Timothy, Jonathan May, and Herman Ruijsenaars. "Supplementary laser firing for combustion stability." U.S. Patent Application No. 14/767,484

[25] McDonell, V. G., and Samuelsen, G. S., 2000, "Measurement of Fuel Mixing and Transport Processes in Gas Turbines Combustion,” J. Meas. Sci. Technol., 11(7), pp. 870-886.

[26] Morsy, M. H., \& Chung, S. H. (2003). Laser-induced multipoint ignition with a single-shot laser using two conical cavities for hydrogen/air mixture. Experimental Thermal and Fluid Science, 27(4), 491-497.

[27] Herdin, G., Klausner, J., Wintner, E., Weinrotter, M., Graf, J., \& Iskra, K. (2005, January). Laser ignition: A new concept to use and increase the potentials of gas engines. In ASME 2005 Internal Combustion Engine Division Fall Technical Conference (pp. 673-681). American Society of Mechanical Engineers.

[28] Agbonzikilo, F. E., Stewart, J., Sadasivuni, S. K., Owen, I., Riley, M., and Sanderson, V., 2014, "Experimental and Numerical Investigation of Fuel-Air Mixing in a Radial Swirler Slot of a Dry Low Emission Gas Turbine Combustor," ASME Paper No. GT2014-27099.

[29] Lefebvre, A. H., 1998, Gas Turbine Combustion, 2nd ed., Taylor and Francis, Philadelphia, PA. 
[30] Lee, J. H., Jeon, C. H., Chang, Y. J., Park, C. W., and Habn, J. W., 2005, "Experimental Study on Flame Structure and Temperature Characteristics in a Lean Premixed Model Gas Turbine Combustor," J. Mech. Sci. Technol. (KSME Int. J.), 19(6), pp. 1366-1377.

[31] Lam, K., Geipel, P., and Larfeldt, L., 2014, "Hydrogen Enriched Combustion

[32] Testing of Siemens Industrial SGT-400 at Atmospheric Conditions," ASME J. Eng. Gas Turbines Power, 137(2), p. 021502.

[33] Gupta, A. K., Lilley, D. G., and Syred, N., 1984, Swirl Flow, Abacus Press, Preston, UK

[34] Nirmolo, A., 2007, "Optimization of Radial Jets Mixing in Cross-low of Combustion Chambers Using Computational Fluid Dynamics," Ph.D. thesis, Otto-von-Guericke-University of Magdeburg, Magdeburg, Germany

[35] Hatch, M. S., Sowa, W. A., and Samuelsen, G. S., 1996, "Influence of Geometry and Flow Variation on Jet Mixing and NO Formation in a Model Staged Combustor Mixer With Eight Orifices," NASA Lewis Research Centre, Cleveland, OH, NASA Report No. 194473.

[36] Kandakure, M. T., Patkar, V. C., Patwardhan, A. W., and Patwardhan, J. A., 2009, "Mixing With Jets in Cross-Flow," J. Ind. Eng. Chem. Res., 48(14), pp. 6820-6829.

[37] Muppidi, S., and Mahesh, K., 2006, "Passive Scalar Mixing in Jets in CrossFlow," AIAA Paper No. 2006-1098.

[38] Denev, J. A., Frohlich, J., and Bockhorn, H., 2009, "Large Eddy Simulation of a Swirling Transverse Jet Into a CrossFlow With Investigation of Scalar Transport,” J. Phys. Fluids, 21(1), p. 015101.

[39] ] Javadi, K., Taeibi, M., and Darbandi, M., 2007, "Jet-IntoCrossflow BoundaryLayer Control: Innovation in Gas Turbine Blade Cooling," AIAA J., 45(12), pp. 2910-2925.

[40] Doerr, T. H., Blomeyer, M., and Hennecke, D. K., 1995, "Optimization of Multiple Jets Mixing With Confined CrossFlow," ASME Paper No. 95-GT313 